\title{
Meta
}

Journal des traducteurs

Translators' Journal

Balliu, C. (2005) : Les confidents du Sérail. Les interprètes

français du Levant à l'époque classique, Beyrouth, Université de Saint-Joseph, coll. "Sources-Cibles », 193 p.

\section{Hugo Marquant}

Volume 52, numéro 2, juin 2007

URI : https://id.erudit.org/iderudit/016081ar

DOI : https://doi.org/10.7202/016081ar

Aller au sommaire du numéro

Éditeur(s)

Les Presses de l'Université de Montréal

ISSN

0026-0452 (imprimé)

1492-1421 (numérique)

Découvrir la revue

Citer ce compte rendu

Marquant, H. (2007). Compte rendu de [Balliu, C. (2005) : Les confidents du

Sérail. Les interprètes français du Levant à l'époque classique, Beyrouth,

Université de Saint-Joseph, coll. « Sources-Cibles », 193 p.] Meta, 52(2), 365-367.

https://doi.org/10.7202/016081ar d'utilisation que vous pouvez consulter en ligne.

https://apropos.erudit.org/fr/usagers/politique-dutilisation/ 
ment, depuis le début du XIX ${ }^{\mathrm{e}}$ siècle, le nombre croissant d'ouvrages scientifiques, historiques et sociologiques traduits de langues européennes vers l'arabe ont conduit à une modification lexicale, grammaticale et sémantique de cette langue, qui l'amène à se rapprocher progressivement des langues de départ. Le capitalisme industriel transforme ainsi non seulement les modes de production, mais également l'approche de la connaissance et le style de vie du tiers-monde et de ses formes de langages. Et plus le fossé est grand entre la langue de départ et la langue d'arrivée, plus grand aussi est le danger pour le traducteur de rendre explicite pour le lecteur ce qui reste implicite dans une culture primitive. Dans ce cas, le traducteur risque fort de devenir l'auteur véritable du texte traduit, cédant à la tentation de facilité consistant à rapprocher la culture trouvée dans le texte original de la culture de son lecteur plutôt que, tâche beaucoup plus difficile, d'amener son lecteur à se pénétrer de la culture de l'œuvre originale, que celle-ci soit orale ou écrite.

Translation - Theory and Practice nous offre à la fois un passionnant voyage de découverte de la traduction au fil des siècles ainsi qu'un remarquable abrégé des théories qui lui sont associées et qui oscillent depuis l'Antiquité entre la fidélité à la pensée de l'auteur et le respect dû au texte de départ.

Le seul reproche que nous pourrions adresser à cet ouvrage est de ne pas préciser, sauf pour quelques remarques dans la postface, les critères qui ont présidé au choix des traducteurs retenus. Si certains, comme Martin Luther ou Friedrich Schleiermacher, s'imposaient dans la première période, on ne peut en dire autant de ceux du $\mathrm{xx}^{\mathrm{e}}$ siècle, surtout lorsqu'il s'agit d'auteurs pour qui la traduction n'était pas la principale activité.

Par ailleurs, le lecteur féru de poésie sera heureux de trouver dans cette anthologie de nombreuses pages consacrées à la traduction de cette forme littéraire et aux difficultés épouvées par les traducteurs soucieux à la fois de sonorité et de sémantique chaque fois qu'il doivent rendre et le sens et la musicalité d'un texte.

Serge Marcoux

Université de Montréal, Montréal, Canada

\section{NOTES}

1. Peter France (ed), The Oxford Guide to Literature in English Translation, Oxford, Oxford University Press, 2000.

2. Charles Tomlinson (ed), The Oxford Book of Verse in English Translation, Oxford, Oxford University Press, 1980.

3. Généralement appelée «La Septante».

4. Genèse, chapitre 11, versets 1-9.

Balliu, C. (2005): Les confidents du Sérail. Les interprètes français du Levant à l'époque classique, Beyrouth, Université de Saint-Joseph, coll. «Sources-Cibles», 193 p.

La traduction (traduction écrite) et l'interprétation (traduction orale) n'ont pas toujours fait l'objet d'une distinction technique et méthodologique aussi claire et nette que maintenant. En effet, ce n'est finalement qu'au $\mathrm{xx}^{\mathrm{e}}$ siècle que l'interprétation a pris cette dimension qualitative et professionnelle qui l'a transformée à part entière en activité exclusive et autonome: la naissance et le développement du concept, de la pratique et de la pédagogie de l'interprétation de conférence.

À l'époque classique, par contre, la conception de l'interprétation était encore nettement plus «riche». Elle dépassait de loin les «fonctionnalismes» restrictifs des définitions, des 
procédures et des codes de conduite actuels. Or, le titre et la thématique du nouveau livre du professeur Christian Balliu se situent parfaitement dans cet ordre d'idées: l'interprétation dans son double rôle social (politique, diplomatique, économique, commercial) et culturel (linguistique, littéraire) en référence à l'époque classique et aux rapports entre la France et le Levant. Bien entendu, au cœur de cette étude figure l'artisan par excellence de ces truchements: le «drogman» et/ou l'interprète d'intérêts qu'il n'est pas toujours facile de deviner, voire de spécifier.

Dans sa recherche, qui est en quelque sorte le pendant «interprétation» de son premier livre Les traducteurs transparents, l'auteur aborde son sujet sous trois angles différents: celui du cadre historique (les événements, les acteurs, les contextes); l'angle de la signification (langue et culture, aspects traductologiques) et, enfin, celui du cadre opérationnel (formation et pratique professionnelle).

Même si l'histoire remonte aux Croisades, elle démarre vraiment au XvI $\mathrm{I}^{\mathrm{e}}$ siècle avec Soliman le Magnifique et François I I ${ }^{\text {er }}$. Elle continue avec Colbert et Louis XIV au XVII ${ }^{\mathrm{e}}$ siècle. Elle reprend au $\mathrm{XVIII}^{\mathrm{e}}$ siècle pour s'essouffler finalement dans la première moitié du $\mathrm{XIX}^{\mathrm{e}}$ siècle.

Cette histoire, qui est parsemée de références à toute une série de personnages, d'institutions et de dates représentatives, nous apparaît dans un premier temps comme étant surtout de nature politique, diplomatique, économique, commerciale et sociale. Dans le fond, elle est cependant beaucoup plus humaine et personnelle. Le professeur Balliu s'intéresse en effet à tout moment à l'ensemble des aspects culturels qui la sous-tendent: la culture des hommes, des familles, des dynasties. En fait, il reprend ainsi les deux compétences de base de tout interprète: la connaissance des langues en présence (le problème de l'acquisition linguistique) et l'étude des contextualités pertinentes (maturité, expérience de vie, capacités diplomatiques, culture du pays d'accueil). Or, la clé d'accès méthodologique pratiquée par notre auteur est tout naturellement la formation avec son double visage de contenus programmatiques et de documentation de référence (dont la traductologie). En d'autres mots, dans toute son étude, notre auteur, formateur et traductologue lui-même, s'appuie sans relâche sur les écoles (des Capucins à Péra en passant par Louis le Grand jusqu'à l'Inalco) et la documentation traductologique (bibliothèques, grammaires et dictionnaires, traductions). C'est pourquoi, entre autres, il relève les «sciences accessoires nécessaires à l'état de drogman» (programme) et le fait que de nombreux interprètes deviennent professeurs de langues ou d'interprétation en fin de carrière (pédagogie).

Enfin, sur le plan opérationnel, le professeur Balliu étudie minutieusement le rôle distinctif (médiation interlinguistique versus représentation) et le statut (carrière diplomatique, habillement, émoluments, considération sociale) des interprètes. Il s'intéresse également aux rapports existant entre la traduction orale et la traduction écrite: "Quoi de plus normal que des spécialistes de la traduction orale s'attaquent aussi, de temps à autre, à la traduction écrite» (p. 121) (l'ordre des mots portant ici toute son importance). Et finalement, il fait allusion à toute une série de caractéristiques techniques de la profession: statut des langues (interprètes indigènes/interprètes français) (importance du français), typologie de l'interprétation (liaison?), déontologie (intégrité, fidélité).

Le résultat de cette triple approche est un tableau particulièrement vivant et diversifié où alternent et se succèdent Soliman le Magnifique, François ${ }^{\mathrm{er}}$, Janus Bei, Murad Beg, Louis XIV, Molière et les turqueries, Antoine Galland, les Pétis de la Croix, la Sublime Porte, le Sérail, la Bibliothèque orientale, Laurent d'Arvieux, Jean-Baptiste Adanson, Colbert, les couvents des pères capucins à Péra, Alexandre Mavrocordato, Louis XIV et le Collège de Clermont, les jésuites, Louis le Grand, les Enfants de Langues, Louis Langlès, les Échelles du Levant, les Fonton, les Fornetti, les Galland, les de Fiennes, Louis XV, la Bibliothèque royale et tant d'autres qui retrouvent au sein de ce même tableau soit leur emplacement spécifique, soit leur rôle représentatif. 
En conclusion, l'on peut dire que le professeur Balliu a réussi une nouvelle fois le projet qu'il s'était proposé. Sa double passion de l'époque classique et de l'Orient y sera certainement pour quelque chose. Avec, en complément, ses connaissances de formateur et de traductologue. Si, de plus, il réussit à nous communiquer son admiration (par exemple, pour Les Mille et Une Nuits d'Antoine Galland), nous le devons sans aucun doute à une érudition intégrée et mûrie et à un style élégant et parfaitement communicatif, qui «prend».

Hugo Marquant Institut Libre Marie Haps, Bruxelles, Belgique 